\title{
Relação entre heterogeneidade ambiental e distribuição de espécies em uma floresta paludosa no Município de Cristais Paulista, SP, Brasil
}

\author{
Aloysio de Pádua Teixeira ${ }^{1,3}$ e Marco Antonio Assis ${ }^{2}$
}

Recebido em 2/07/2008. Aceito em 19/12/2008

RESUMO - (Relação entre heterogeneidade ambiental e distribuição de espécies em uma floresta paludosa no Município de Cristais Paulista, SP, Brasil). Neste estudo foi caracterizada a composição florística e fitossociológica de uma floresta paludosa no nordeste do Estado de São Paulo, onde variações no padrão de drenagem ocorrem principalmente no sentido perpendicular ao curso d'água, em função da topografia. Nosso objetivo foi investigar a distribuição das espécies em relação ao substrato e a entrada de luz na comunidade. Foram alocadas 60 parcelas de $10 \times 10 \mathrm{~m}$, distribuídas em seis grupos de 10 parcelas cada. Em cada parcela foram medidos e identificados os indivíduos com PAP $\geq 10 \mathrm{~cm}$, avaliadas as propriedades químicas e granulometria do solo, o desnível topográfico, a drenagem e a abertura do dossel. Foram registradas 88 espécies, das quais 61 foram observadas nas parcelas. Uma análise de correspondência canônica (CCA) indicou correlações entre a distribuição das 29 espécies mais abundantes e drenagem, desnível topográfico e Fe no eixo 1 e abertura do dossel no eixo 2. O coeficiente de Spearman indicou correlações significativas entre 66\% das 29 espécies e profundidade do lençol freático ou abertura do dossel. Como exemplo, Calophyllum brasiliense e Xylopia emarginata prevaleceram em solos mal drenados; Siphoneugena densiflora e Virola sebifera em solos bem drenados; Myrcia laruotteana e Xylopia sericea em parcelas com maior abertura de dossel. A heterogeneidade ambiental foi um importante fator na determinação da distribuição e a coexistência de espécies, resultando em um incremento na diversidade local.

Palavras-chave: abertura de dossel, drenagem, floresta de galeria inundável, mata de brejo, regime de inundação

ABSTRACT - (Floristic composition and relationship between environmental heterogeneity and species distribution in a swamp forest from Cristais Paulista, São Paulo State, Brazil). In the present study, we characterized the floristic composition and tree structure of a swamp forest in northeast of São Paulo State, Brazil, where the drainage pattern changes mainly across the watercourse due to the topography. We aimed to investigate the species distribution in relation to substrate and light entrance in the community. Sixty quadrats $(10 \times 10 \mathrm{~m})$ were divided into six groups of 10 plots. In each quadrat, individuals with $\mathrm{PBH} \geq 10 \mathrm{~cm}$ were measured and identified. We also evaluated soil chemical properties, granulometry, topographic unevenness, drainage, and canopy openness. Eighty-eight species were recorded, from which 61 were detected in the quadrats. Canonical correspondence analysis (CCA) indicated correlations between the distribution of the 29 most abundant species and drainage, topographic unevenness and $\mathrm{Fe}$ in the axis 1, and canopy openness in the axis 2. Spearman's rank correlation coefficient indicated significant correlations between $66 \%$ from the 29 species and water table depth or canopy openness. As examples, Calophyllum brasiliense and Xylopia emarginata were predominant in poorly-drained soils; Siphoneugena densiflora and Virola sebifera, in the drained ones; and Myrcia laruotteana and Xylopia sericea, in the quadrats presenting higher canopy openness. Environmental heterogeneity showed to be an important factor in determining the species distribution and coexistence, which increases local diversity.

Key words: canopy openness, drainage patterns, flooding regime, gallery swamp forest

\section{Introdução}

As florestas paludosas caracterizam-se pela presença de água na superfície do solo em caráter quase permanente ao longo do ano, em função do afloramento do lençol freático, em baixadas, depressões, cabeceiras e margens dos cursos d'água. Em função da ocorrência restrita a solos hidromórficos, ocorrem em manchas associadas a outras formações vegetacionais, como savanas ou cerrados (Oliveira Filho et al. 1990), florestas estacionais semideciduais (Teixeira et al. 2008), florestas ombrófilas densas (Lieberman et al. 1985; Scarano 2002) e ainda isoladas em meio à agricultura e pastagens. Apesar de sua ampla ocorrência geográfica, a especificidade dos solos em que ocorrem determina a essas florestas o caráter de clímax edáfico (Scarano 2002). São ecossistemas extremamente frágeis e vulneráveis a ações antrópicas, fundamentais para a conservação e proteção dos recursos hídricos, da fauna terrestre e aquática, porém bastante degradados no sudeste do Brasil (Torres et al. 1994; Ivanauskas et al. 1997; Teixeira et al. 2008).

A saturação hídrica dos solos nas florestas paludosas determina um ambiente altamente seletivo para as espécies vegetais, em função da pouca ou inexistente oxigenação (Lieberman et al. 1985; Joly 1991). Nesse ambiente estressante, prevalecem poucas espécies arbóreas, que concentram muitos indivíduos e elevada biomassa, e determinam uma floresta com diversidade menor do que florestas estabelecidas sobre solos melhor drenados (van Andel 2003; Koponen et al. 2004; Teixeira \& Assis 2005; Scarano 2006). Variações no padrão de drenagem nessas florestas são observadas em função do desnível topográfico ao longo (Teixeira \& Assis 2005; Teixeira et al. 2008) ou perpendicular ao curso d'água (Marques et al. 2003), ou em função de variações microtopográficas associadas à variação da profundidade do lençol freático, que promovem um mosaico de microsítios com solos bem drenados (montículos), poças permanentes e canais naturais temporários ou permanentes de água corrente (Ivanauskas et al. 1997; Scarano et al. 1997; Toniato et al. 1998; Paschoal \& Cavassan 1999; Souza \& Martins 2005).

A presença de sítios de melhor drenagem pode determinar o incremento da diversidade local da flora das florestas paludosas, por meio do estabelecimento de espécies menos tolerantes à saturação hídrica, que prevalecem nas formações florestais circundantes (Scarano 2002; Marques et al. 2003;

\footnotetext{
1 Universidade Estadual Paulista, Programa de Pós-Graduação em Ciências Biológicas (Biologia Vegetal), Rio Claro, SP, Brasil

2 Universidade Estadual Paulista, Departamento de Botânica, Rio Claro, SP, Brasil

3 Autor para correspondência: aloysioteixeira@yahoo.com.br
} 
Rocha et al. 2005; Teixeira et al. 2008). Dessa forma, diferenças florísticas e estruturais podem ser observadas dentro de um mesmo remanescente, em função das diferentes condições de drenagem (Loures et al. 2007; Teixeira et al. 2008) e entre diferentes remanescentes desse tipo florestal, conforme a influência da vegetação circundante (Costa et al. 1997; Ivanauskas et al. 1997; Paschoal \& Cavassan 1999; Teixeira \& Assis 2005). Embora a relação entre a estruturação da comunidade de plantas e as variações ambientais locais tenha sido explorada em diferentes florestas ribeirinhas (e.g. Oliveira Filho et al. 1990; Felfili 1995; Damasceno Junior et al. 2005), a heterogeneidade interna das florestas paludosas têm sido negligenciada (Souza \& Martins 2005) e pouco se sabe sobre a distribuição das espécies arbóreas em relação a características ambientais, considerando uma pequena escala espacial.

Este estudo analisou a composição da flora e a estrutura fitossociológica do componente arbustivo-arbóreo de uma floresta paludosa. Essa floresta ocorre nas margens de um córrego e são observadas variações no padrão de drenagem principalmente no sentido perpendicular ao curso d'água, em função da topografia. Nosso objetivo foi investigar as relações entre a composição florística e a heterogeneidade ambiental da floresta, relacionada ao substrato e a entrada de luz na comunidade, considerando uma escala espacial reduzida (poucas centenas de metros). Nossas expectativas eram de que as condições edáficas e a composição florística da floresta variassem com a topografia e que a drenagem do solo pudesse ser o principal fator responsável pela distribuição das espécies na floresta.

\section{Material e métodos}

Caracterização da área de estudo - A floresta paludosa (20²5'33"'S, $47^{\circ} 26^{\prime} 01^{\prime}$ 'W) localiza-se na fazenda Tamboril (antiga fazenda Samello), no Município de Cristais Paulista, porção nordeste do Estado de São Paulo. Cristais Paulista está inserida no Planalto de Franca, entre as cotas de 950 e $1.050 \mathrm{~m}$ de altitude, com orientação no sentido norte-sul, estendendo-se de Franca a Pedregulho. Este Planalto constitui o primeiro dos grandes planaltos de reverso de cuesta interna, no nordeste do Estado, situado entre os rios Grande e Sapucaí, e apresenta topografia uniforme a suavemente ondulada (Almeida 1974). O clima do Município enquadra-se no tipo "Cwb" de Köppen (Setzer 1966) e é caracterizado por duas estações bem definidas, sendo uma seca, de abril a setembro, e outra chuvosa, de outubro a março. A precipitação média anual é de $1.591 \mathrm{~mm}$, com cerca de $82 \%$ das chuvas distribuídas na estação chuvosa (dados do Centro de Pesquisas Meteorológicas e Climáticas Aplicadas a Agricultura - Unicamp). A temperatura média do mês mais frio (julho) é de $17,1^{\circ} \mathrm{C}$ e do mês mais quente (fevereiro) é de $22,2^{\circ} \mathrm{C}$. Na região, a vegetação é caracterizada pela ocorrência de cerrados entremeados por florestas, sendo que diferentes fitofisionomias de cerrado (senso Ribeiro \& Walter 1998) estão associadas principalmente aos interflúvios, e remanescentes de floresta estacional semidecidual se encontram em encostas mais íngremes e próximas aos cursos d'água.

A floresta paludosa estudada pode ser denominada de floresta de galeria inundável (senso Ribeiro \& Walter 1998), floresta latifoliada higrófila ou mata de brejo (senso Leitão Filho 1982). O remanescente florestal, com cerca de 10 ha, ocupa o entorno da nascente e ambas as margens de um afluente do ribeirão dos Cristais, que pertence à bacia hidrográfica do Rio Grande. O remanescente ocupa um trecho contínuo de cerca de $1,7 \mathrm{~km}$, com as cotas altitudinais variando de 1.000 a
$945 \mathrm{~m}$ ao longo do curso d'água, porém em uma faixa marginal que não ultrapassa os $80 \mathrm{~m}$ de largura. As principais variações topográficas e no padrão de drenagem do remanescente são observadas no sentido transversal ao curso d'água: relevo plano nas margens do córrego, com solos permanentemente saturados ou com lençol freático próximo a superfície mesmo na estação seca; e alguns trechos mais distantes do curso d'água, com aclive no sentido interior-borda, com o lençol freático menos superficial e água drenada mais rapidamente. Manchas de cerrado sensu stricto podem ser observadas na borda da floresta, sobre solos bem drenados e textura mais arenosa.

O remanescente é circundado principalmente por pastagem, sendo que o gado adentra no interior da floresta em busca de água e sombra. Em menor proporção, o plantio homogêneo de eucaliptos faz interface com o remanescente. A estratificação vertical da floresta é caracterizada pelo dossel com altura entre 12 e $15 \mathrm{~m}$, e predomínio de Calophyllum brasiliense, Tapirira guianensis, Xylopia emarginata e Protium spruceanum; árvores emergentes, representadas pelas três primeiras espécies, que eventualmente atingem altura superior a $20 \mathrm{~m}$; estrato inferior, com altura entre 3 e $7 \mathrm{~m}$, determinado principalmente por Geonoma brevispatha, Guarea macrophylla, Myrcia laruotteana e Pseudolmedia laevigata; e estrato herbáceo-subarbustivo, pouco conspícuo, representado principalmente por Blechnum brasiliense. Lianas e epífitas são pouco comuns, sendo que as primeiras são observadas principalmente nas bordas da floresta.

Procedimento de campo - Os trabalhos de campo estenderam-se de janeiro/2006 até abril/2008. Para a caracterização do componente arbustivo-arbóreo da floresta paludosa foram instaladas 60 parcelas de $10 \mathrm{~m} \times 10 \mathrm{~m}$, distribuídas em seis trechos distantes de 130 a $350 \mathrm{~m}$ entre si. Em cada trecho, um grupo de 10 parcelas foi estabelecido procurando abranger diferentes condições ambientais relacionadas à topografia e ao padrão de drenagem, que variam principalmente no sentido perpendicular ao curso d'água. A distribuição das parcelas em cada trecho deu-se de forma variada (Fig. 1), conforme a largura da floresta e as condições da vegetação, evitando-se trechos alterados em decorrência de quedas de grandes árvores ou entrada de gado, por exemplo. Em cada parcela foram amostrados os indivíduos com perímetro à altura do peito $(\mathrm{PAP}) \geq 10 \mathrm{~cm}$. Indivíduos perfilhados foram incluídos na amostragem quando a soma da área basal dos caules correspondeu a área basal de um indivíduo com PAP $\geq 10 \mathrm{~cm}$. Visando ao complemento do levantamento florístico, foram feitas coletas de material reprodutivo de indivíduos não amostrados nas parcelas. As espécies foram listadas em famílias de acordo com o sistema de classificação do "Angiosperm Phylogeny Group" (APG II 2003).

O solo de cada parcela foi classificado em campo, de acordo com o Sistema Brasileiro de Classificação de Solos (Embrapa 1999). Com auxílio de um trado foram coletadas amostras no centro de cada parcela, até a profundidade de $1 \mathrm{~m}$, e avaliadas as principais variações quanto à coloração e textura nos perfis do solo. Para a análise das condições químicas e granulometria dos solos, foram coletadas amostras em cinco pontos por parcela, a uma profundidade de 0 a $20 \mathrm{~cm}$ : no centro e próximo de cada vértice. As amostras de solo de cada parcela foram misturadas para obter-se uma amostra composta de cerca de 0,5 L, sendo posteriormente submetidas ao Centro de Ciências Agrárias da UFSCar, Campus de Araras, para análise química no Laboratório de Análise Química de Solo e Planta, e análise granulométrica no Laboratório de Física do Solo. Foram calculados os teores de Fósforo $(\mathrm{P})$, matéria orgânica humificada, pH, Potássio (K), Cálcio (Ca), Magnésio $(\mathrm{Mg})$, acidez potencial $(\mathrm{H}+\mathrm{Al})$, Alumínio $(\mathrm{Al})$, saturação por Alumínio (m), soma de bases (SB), capacidade de troca catiônica (CTC), saturação por bases (V), Enxofre (S), Boro (B), Cobre (Cu), Ferro ( $\mathrm{Fe}$ ), Manganês $(\mathrm{Mn})$ e Zinco $(\mathrm{Zn})$. Os procedimentos para análise química seguiram Raij (1983). Como a maioria das amostras apresentou elevados teores de matéria orgânica, as amostras tiveram que ser incineradas com o auxílio de uma mufla, a uma temperatura de $500{ }^{\circ} \mathrm{C}$, por três horas, para eliminação do material orgânico e posterior determinação da porcentagem de argila, areia e silte.

As parcelas foram enquadradas em classes de declividade, conforme o declive no sentido perpendicular ao curso d'água. As classes consideradas foram: declive $\leq 5 \%$, entre 5 e $10 \%$ e declive entre 10 e $15 \%$. As condições de drenagem foram avaliadas de acordo 


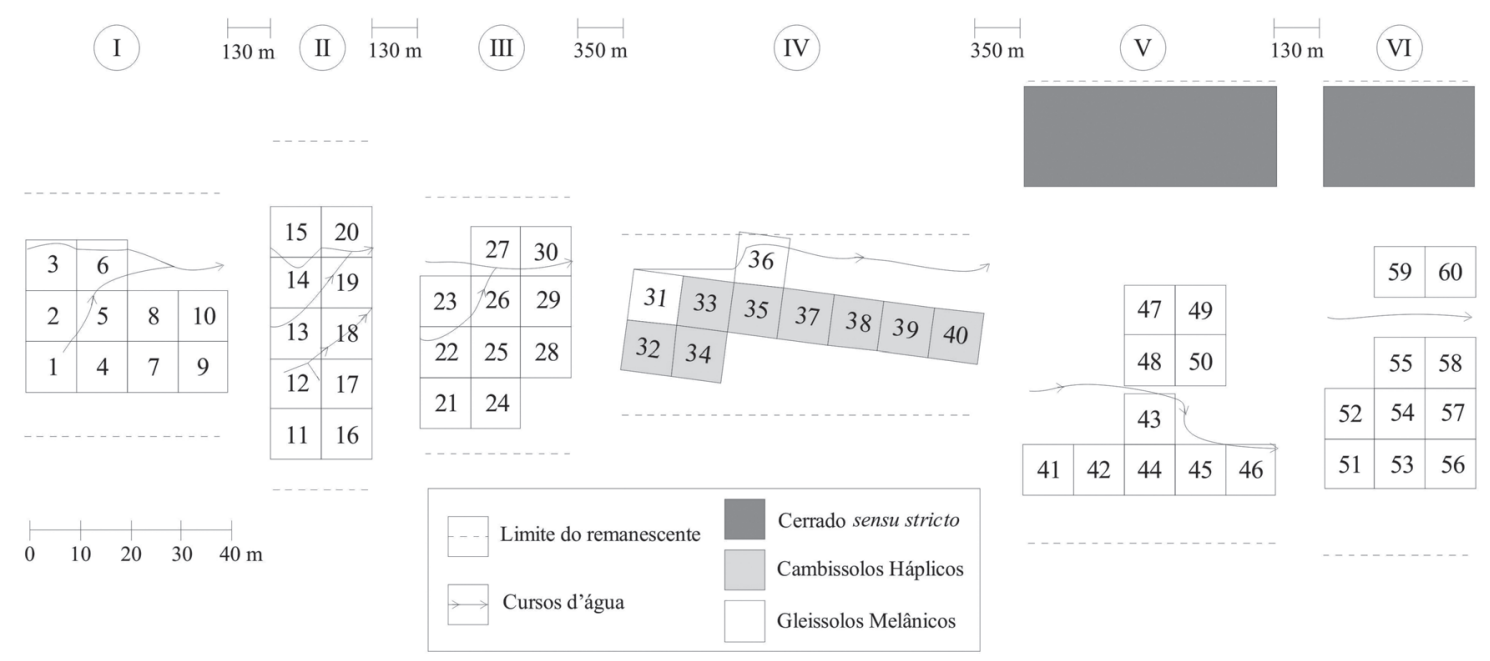

Figura 1. Mapa com a distribuição de 60 parcelas, em seis trechos, utilizadas para amostragem do componente arbustivo-arbóreo de uma floresta paludosa no Município de Cristais Paulista, Estado de São Paulo, Brasil.

com a porcentagem da área da parcela com alagamento (água acima da superfície do solo) e com a profundidade do lençol freático. Cada parcela foi arbitrariamente classificada em classes de alagamento, sendo consideradas cinco classes: sem alagamento, área da parcela alagada entre 1 e $25 \%$, entre 25 e $50 \%$, entre 50 e $75 \%$ e entre 75 e $100 \%$. Com o propósito de diminuir o erro da estimativa da área alagada, cada parcela foi dividida em quatro sub-parcelas de $5 \times 5 \mathrm{~m}$. Esses registros foram tomados na estação seca (setembro/2007) e novamente na estação chuvosa (fevereiro/2008). Em setembro/2007, a profundidade do lençol freático foi medida, no centro de cada parcela, com uma vara graduada de $1 \mathrm{~m}$. Para essa medição foi aproveitada a tradagem utilizada para a classificação dos solos.

A entrada de luz na comunidade foi representada, em cada parcela, pela porcentagem de abertura do dossel. Os valores foram determinados pela média de duas fotografias por parcela, obtidas com máquina fotográfica e um tripé de $1,25 \mathrm{~m}$ de altura, filme e lente hemisférica "olho de peixe" Nikon de $16 \mathrm{~mm}$. As fotografias foram digitalizadas e a porcentagem da abertura do dossel foi estimada no programa GLA (Gap Light Analyzer) versão 2 (Frazer et al. 1999), sendo que foi considerada apenas a parte central equivalente à cerca de $1 / 9$ da foto. Análise dos dados - Foram encontrados dois tipos de solo na área de estudo, de forma que os descritores fitossociológicos foram calculados para cada tipo de solo. Os cálculos foram processados no programa Fitopac (Shepherd 1994) e os descritores utilizados foram os valores absolutos de densidade, dominância e frequiência, os índices de valor de importância (VI) e de diversidade de Shannon (H'), considerando a base logarítmica natural, e a eqüabilidade de Pielou (J'). Como um número distinto de parcelas foi alocado em cada tipo de solo, o número de espécies e famílias esperadas para o solo com menor esforço amostral foi calculado por meio de uma rarefação, utilizando-se o programa Analytic Rarefaction 1.3.

As variáveis ambientais foram comparadas entre os dois tipos de solo por meio de testes não paramétricos (Mann-Whitney, $U$ ), visto que não foram verificadas normalidade e homocedasticidade dos dados residuais. Para as variáveis enquadradas em classes (desnível topográfico e alagamento), foi considerado, para cada parcela, o ponto médio por classe. Para o desnível topográfico, os valores considerados foram 2,5 (para parcelas com desnível $\leq 5 \%$ ), 7,5 (para desnível entre 5 e 10\%) e 12,5 (para desnível entre 10 e 15\%). Para a área alagada, foram atribuídos os valores zero para parcelas não alagadas, 12,5 para parcelas alagadas entre 1 e $25 \%, 37,5$ para alagamento entre 25 e $50 \%, 62,5$ para alagamento entre 50 e $75 \%$ e 87,5 para parcelas alagadas entre 75 e $100 \%$. Os testes foram processados no SYSTAT 11 (SYSTAT Software Inc).

As inter-relações entre abundância das espécies, propriedades químicas e granulometria dos solos, desnível topográfico, área alagada, profundidade do lençol freático e abertura do dossel foram avaliadas por meio de uma análise de correspondência canônica - CCA (Ter Braak 1987). Para essa análise foi construída uma matriz de espécies e uma de variáveis ambientais. A matriz de espécies foi constituída pelo número de indivíduos por espécie (variáveis) em cada parcela (objetos), sendo utilizadas as espécies com cinco ou mais indivíduos na amostragem total (29 espécies). A matriz de dados ambientais incluiu as propriedades químicas do solo, a granulometria, as classes de desnível topográfico e alagamento na estação seca e na estação chuvosa, a profundidade do lençol freático na estação seca e a porcentagem de abertura do dossel por parcelas. Foi processada uma análise preliminar com todas as variáveis ambientais e, posteriormente, foram excluídas aquelas pouco correlacionadas com os eixos da ordenação (correlação abaixo de 0,5) e aquelas multicolineares (correlação entre variáveis acima de 0,7). Dessa forma, as variáveis restantes utilizadas na CCA final foram $\mathrm{Fe}$, área alagada na estação chuvosa, profundidade do lençol freático, desnível topográfico e abertura do dossel. A hipótese de independência entre as matrizes de abundância de espécies e de variáveis ambientais foi avaliada pelo teste de Mantel, por meio de 1000 permutações de Monte Carlo (Ter Braak 1987). Para processar as análises multivariadas foi utilizado o programa PC-ORD versão 4.0 (McCune \& Mefford 1999). O coeficiente de Spearman $\left(r_{s}\right)$, juntamente com a correção seqüencial de Bonferroni, foi utilizado para avaliar a correlação entre as 29 espécies mais abundantes e duas variáveis ambientais (mais correlacionadas com os eixos 1 e 2 da CCA), considerando significativo o $P \leq 0,05$ ( $\leq 0,025$ após correção).

\section{Resultados}

Variáveis ambientais - Os solos observados na floresta paludosa foram: Cambissolos Háplicos ( $\mathrm{n}=8$ parcelas), nos trechos de maior declive e distantes do curso d'água; e Gleissolos Melânicos, nas áreas planas que margeiam o curso d'água e em algumas parcelas sobre maior declividade ( $n$ = 52 parcelas). Os Cambissolos são constituídos por material mineral e horizonte $\mathrm{B}$ incipiente, com coloração amarronzada. Os Gleissolos são caracterizados pelo horizonte glei mineral, de cor cinzenta, decorrente da presença de Fe reduzido.

Das 27 variáveis ambientais, 59\% apresentaram diferenças significativas entre os tipos de solo (Tab. 1). Os Gleissolos apresentaram maior concentração de bases trocáveis ( $\mathrm{K}, \mathrm{Ca}$ e $\mathrm{Mg}$ ), de alguns micronutrientes (B, Cu e 
Tabela 1. Variáveis físico-químicas, alagamento, profundidade do lençol freático e abertura do dossel relacionadas a dois tipos de solo de uma floresta paludosa no Município de Cristais Paulista, Estado de São Paulo, Brasil. Os valores representam médias seguidas do desvio padrão. Médias seguidas por letras distintas indicam diferenças significativas entre si pelo teste de Mann-Whitney (* $P \leq 0,05, * * P \leq 0,01)$. Ns = não significativo; Na = não se aplica, por não ter variância da média.

\begin{tabular}{|c|c|c|c|}
\hline Variáveis ambientais & Cambissolos $(\mathrm{n}=8)$ & Gleissolos $(\mathrm{n}=52)$ & Mann-whitney $U$ test \\
\hline $\mathrm{P}\left(\mathrm{mg} \cdot \mathrm{dm}^{-3}\right)$ & $6,0 \pm 1,1$ & $6,5 \pm 2,4$ & $\mathrm{~ns}$ \\
\hline Matéria orgânica humificada $\left(\mathrm{g} \cdot \mathrm{dm}^{-3}\right)$ & $37,5 \pm 11,5 \mathrm{a}$ & $72,1 \pm 31,7 \mathrm{~b}$ & $* *$ \\
\hline $\mathrm{pH}\left(\mathrm{em} \mathrm{CaCl}_{2}\right)$ & $3,9 \pm 0,2$ & $4,0 \pm 0,2$ & ns \\
\hline $\mathrm{K}\left(\mathrm{mmol}_{\mathrm{c}} \cdot \mathrm{dm}^{-3}\right)$ & $1,0 \pm 0,1 \mathrm{a}$ & $1,5 \pm 0,6 \mathrm{~b}$ & $*$ \\
\hline $\mathrm{Ca}\left(\mathrm{mmol}_{\mathrm{c}} \cdot \mathrm{dm}^{-3}\right)$ & $1,0 \pm 0,0$ & $4,8 \pm 4,7$ & na \\
\hline $\operatorname{Mg}\left(\mathrm{mmol}_{\mathrm{c}} \cdot \mathrm{dm}^{-3}\right)$ & $1,1 \pm 0,3 \mathrm{a}$ & $2,8 \pm 2,0 b$ & $* *$ \\
\hline $\mathrm{H} \pm \mathrm{Al}\left(\mathrm{mmol}_{\mathrm{c}} \cdot \mathrm{dm}^{-3}\right)$ & $103,4 \pm 16,3$ & $110,3 \pm 33,4$ & ns \\
\hline $\mathrm{Al}\left(\mathrm{mmol}_{\mathrm{c}} \cdot \mathrm{dm}^{-3}\right)$ & $17,7 \pm 3,1$ & $16,0 \pm 6,1$ & ns \\
\hline $\mathrm{m}(\%)$ & $84,6 \pm 2,4 \mathrm{a}$ & $65,5 \pm 15,5 b$ & $* *$ \\
\hline Soma de bases $\left(\mathrm{mmol}_{\mathrm{c}} \cdot \mathrm{dm}^{-3}\right)$ & $3,2 \pm 0,4 \mathrm{a}$ & $9,2 \pm 7,0 \mathrm{~b}$ & $* *$ \\
\hline $\mathrm{CTC}\left(\mathrm{mmol}_{\mathrm{c}} \cdot \mathrm{dm}^{-3}\right)$ & $106,5 \pm 16,5$ & $119,5 \pm 36,3$ & ns \\
\hline $\mathrm{V}(\%)$ & $3,0 \pm 0,5 \mathrm{a}$ & $7,4 \pm 4,0 \mathrm{~b}$ & $* *$ \\
\hline $\mathrm{S}\left(\mathrm{mg} \cdot \mathrm{dm}^{-3}\right)$ & $6,5 \pm 3,4 \mathrm{a}$ & $15,4 \pm 5,3 b$ & $* *$ \\
\hline B $\left(\mathrm{mg} \cdot \mathrm{dm}^{-3}\right)$ & $0,2 \pm 0,1 \mathrm{a}$ & $0,8 \pm 0,4 b$ & $* *$ \\
\hline $\mathrm{Cu}\left(\mathrm{mg} \cdot \mathrm{dm}^{-3}\right)$ & $1,2 \pm 0,2 \mathrm{a}$ & $0,8 \pm 0,5 b$ & $*$ \\
\hline $\mathrm{Fe}\left(\mathrm{mg} \cdot \mathrm{dm}^{-3}\right)$ & $83,5 \pm 13,4$ a & $212,9 \pm 57,2 b$ & $* *$ \\
\hline $\operatorname{Mn}\left(\mathrm{mg} \cdot \mathrm{dm}^{-3}\right)$ & $16,9 \pm 6,2$ & $18,0 \pm 16,3$ & ns \\
\hline $\mathrm{Zn}\left(\mathrm{mg} \cdot \mathrm{dm}^{-3}\right)$ & $0,6 \pm 0,1$ & $0,9 \pm 0,6$ & ns \\
\hline Argila (\%) & $8,8 \pm 4,1$ & $8,8 \pm 4,8$ & ns \\
\hline Areia $(\%)$ & $72,9 \pm 7,1$ & $60,6 \pm 18,0$ & ns \\
\hline Silte $(\%)$ & $6,5 \pm 2,2 \mathrm{a}$ & $11,7 \pm 7,4 b$ & $*$ \\
\hline Matéria orgânica (\%) & $11,9 \pm 3,4$ & $18,9 \pm 11,1$ & ns \\
\hline Desnível topográfico (\%) & $10,6 \pm 2,6 \mathrm{a}$ & $4,7 \pm 3,5 b$ & $* *$ \\
\hline Área alagada na estação seca (\%) & 0,0 & $15,4 \pm 16,9$ & na \\
\hline Área alagada na estação chuvosa (\%) & $1,6 \pm 4,4 \mathrm{a}$ & $24,8 \pm 21,4 b$ & $* *$ \\
\hline Profundidade do lençol freático $(\mathrm{cm})$ & $-95,9 \pm 5,8 \mathrm{a}$ & $-18,9 \pm 30,4 b$ & $* *$ \\
\hline Abertura do dossel (\%) & $22,8 \pm 3,7$ & $19,9 \pm 6,6$ & ns \\
\hline
\end{tabular}

Fe), matéria orgânica e silte, além de menor desnível topográfico, lençol freático mais superficial na estação seca e maior área alagada tanto na estação seca quanto na chuvosa. Enquanto nos Gleissolos $70 \%$ das parcelas mostraram-se com algum alagamento na estação seca e $80 \%$ na estação chuvosa, nos Cambissolos nenhuma parcela sofreu alagamento na estação seca e 13\% (uma parcela) alagou na estação chuvosa. Como características comuns, os solos apresentaram textura predominantemente arenosa, caráter álico [saturação por alumínio $(\mathrm{m})>50 \%$ ], $\mathrm{pH}$ muito baixo, teor de fósforo $(\mathrm{P})$ semelhante e porcentagem de abertura do dossel em torno de $20 \%$.

Florística e fitossociologia - Nas 60 parcelas foram encontrados 2.036 indivíduos, distribuídos em 61 espécies e 36 famílias. A diversidade de espécies (H') foi de 2,71 e o valor de eqüabilidade (J') foi de 0,66 . Fora das parcelas foram encontradas mais 27 espécies por meio de coletas casuais, totalizando 88 espécies, distribuídas em 41 famílias (Tab. 2). Pela riqueza de espécies destacaram-se Myrtaceae (nove espécies), Rubiaceae (sete), Lauraceae (seis), Annonaceae, Fabaceae, Melastomataceae (cinco) e Arecaceae, Euphorbiaceae, Moraceae e Myrsinaceae (três espécies cada). As famílias que detiveram maior VI foram Burseraceae (19,2\% do total), Clusiaceae (17,7\%), Anacardiaceae (12\%), Annonaceae $(11,1 \%)$ e Arecaceae $(6,7 \%)$. Com exceção de Annonaceae, as famílias mais importantes foram representadas por uma só espécie.

Nos Cambissolos foram quantificados 206 indivíduos (equivalente a 2575 indivíduos.ha $^{-1}$ ), distribuídos em 30 espécies, que pertencem a 21 famílias (Tab. 3). As 10 espécies mais importantes perfizeram $78 \%$ do VI e $80 \%$ da densidade total. O índice de diversidade de Shannon para as espécies $\left(\mathrm{H}^{\prime}\right)$ foi de 2,74 e a eqüabilidade de Pielou (J') foi de 0,81. Nos Gleissolos foram encontrados 1830 indivíduos (correspondendo a 3519 indivíduos.ha ${ }^{-1}$ ), pertencentes a 47 espécies e 30 famílias (Tab. 4). A análise de rarefação indicou que o número de espécies e famílias esperadas para 206 indivíduos, como nos Cambissolos, seria de 23 e 20, respectivamente. As 10 espécies mais importantes somaram $85 \%$ do VI e $89 \%$ da densidade, de forma que a maior dominância ecológica resultou em um menor valor de eqüabilidade $\left(\mathrm{J}^{\prime}=0,65\right)$ e diversidade $\left(\mathrm{H}^{\prime}=2,51\right)$ para os Gleissolos. Espécies como Protium spruceanum e Tapirira guianensis se destacaram em ambos os tipos de solo. Siphoneugena densiflora, Ocotea pulchella, Virola sebifera e Copaifera langsdorffii, entre outras espécies, obtiveram elevados valores de importância nos Cambissolos, enquanto outras espécies como Calophyllum brasiliense, Xylopia emarginata, Geonoma brevispatha e Guarea macrophylla se destacaram nos Gleissolos.

Variáveis ambientais e distribuição das espécies - Altas correlações entre as variáveis ambientais e as espécies foram encontradas para os dois primeiros eixos da ordenação na CCA (82,5\% para o eixo 1 e $63,1 \%$ para o eixo 2 ) e o teste de Mantel indicou que essas correlações foram significativas ( $P=0,002$ para o eixo 1 e $P=0,012$ para o eixo 2 ). O eixo 1 separou as parcelas de acordo com as condições hídricas, desnível topográfico e propriedades químicas dos solos, 
Tabela 2. Espécies arbustivas e arbóreas (PAP $\geq 10 \mathrm{~cm}$ ) encontradas em uma floresta paludosa no Município de Cristais Paulista, SP, Brasil ordenadas por famílias e ambiente de ocorrência: $\mathrm{C}=$ Cambissolos; $\mathrm{G}=$ Gleissolos; $\mathrm{F}=$ fora das parcelas. * Espécie exótica.

\begin{tabular}{|c|c|c|c|c|c|c|c|}
\hline Famílias/Espécies & $\mathrm{C}$ & G & $\mathrm{F}$ & Famílias/Espécies & $\mathrm{C}$ & G & $\mathrm{F}$ \\
\hline ANACARDIACEAE & & & & Tibouchina sp. & & & $\mathrm{x}$ \\
\hline Tapirira guianensis Aubl. & $\mathrm{x}$ & $\mathrm{x}$ & & MELIACEAE & & & \\
\hline T. obtusa (Benth.) J.D. Mitch. & $\mathrm{x}$ & & & Cedrela fissilis Vell. & & & $\mathrm{x}$ \\
\hline ANNONACEAE & & & & Guarea macrophylla Vahl & & $\mathrm{x}$ & \\
\hline Duguetia lanceolata A. St.-Hil. & $\mathrm{x}$ & & & MONIMIACEAE & & & \\
\hline Guatteria nigrescens Mart. & & & $\mathrm{x}$ & Macropeplus ligustrinus (Tul.) Perk. & $\mathrm{x}$ & $\mathrm{x}$ & \\
\hline Xylopia brasiliensis Spreng. & & & $\mathrm{x}$ & MORACEAE & & & \\
\hline X. emarginata Mart. & $\mathrm{x}$ & $\mathrm{x}$ & & Ficus citrifolia Mill. & & & $\mathrm{x}$ \\
\hline$X$. sericea A. St.-Hil. & $\mathrm{x}$ & $\mathrm{x}$ & & F. gomelleira Kunth \& C.D. Bouché & & $\mathrm{x}$ & \\
\hline ARALIACEAE & & & & Pseudolmedia laevigata Trécul & $\mathrm{x}$ & $\mathrm{x}$ & \\
\hline Dendropanax cuneatus Decne \& Planch. & & $\mathrm{x}$ & & MYRISTICACEAE & & & \\
\hline $\begin{array}{l}\text { Schefflera morototoni (Aubl.) Maguire, } \\
\text { Steyerm. \& Frodin }\end{array}$ & & $\mathrm{x}$ & & $\begin{array}{l}\text { Virola sebifera Aubl. } \\
\text { MYRSINACEAE }\end{array}$ & $\mathrm{x}$ & $\mathrm{x}$ & \\
\hline ARECACEAE & & & & Cybianthus densicomus Mart. & & $\mathrm{x}$ & \\
\hline Euterpe edulis Mart. & & & $\mathrm{x}$ & Rapanea ferruginea (Ruiz \& Pav.) Mez & & & $\mathrm{x}$ \\
\hline Geonoma brevispatha Barb. Rodr. & $\mathrm{x}$ & $\mathrm{x}$ & & R. gardneriana (A. DC.) $\mathrm{Mez}$ & $\mathrm{x}$ & & \\
\hline Syagrus romanzoffiana (Cham.) Glassman & & & $\mathrm{x}$ & MYRTACEAE & & & \\
\hline BIGNONIACEAE & & & & Calyptranthes grandiflora O. Berg & & $\mathrm{X}$ & \\
\hline Tabebuia umbellata (Sond.) Sandwith & & & $\mathrm{x}$ & Eugenia acutata Miq. & $\mathrm{x}$ & & \\
\hline BURSERACEAE & & & & Myrcia laruotteana Cambess. & & $\mathrm{X}$ & \\
\hline Protium spruceanum (Benth.) Engl. & $\mathrm{x}$ & $\mathrm{x}$ & & M. cf. palustris DC. & & $\mathrm{x}$ & \\
\hline CHLORANTHACEAE & & & & M. splendens (Sw.) DC. & & & $\mathrm{X}$ \\
\hline Hedyosmum brasiliense Mart. ex Miq. & & $\mathrm{x}$ & & M. tomentosa (Aubl.) DC. & $\mathrm{x}$ & & \\
\hline CHRYSOBALANACEAE & & & & M. venulosa DC. & & $\mathrm{x}$ & \\
\hline Hirtella glandulosa Spreng. & & & $\mathrm{x}$ & Myrciaria floribunda (H. West ex Willd.) O. Berg & $\mathrm{x}$ & & \\
\hline CLUSIACEAE & & & & Siphoneugena densiflora $\mathrm{O}$. Berg & $\mathrm{x}$ & $\mathrm{x}$ & \\
\hline Calophyllum brasiliense Cambess. & $\mathrm{x}$ & $\mathrm{x}$ & & NYCTAGINACEAE & & & \\
\hline CYATHEACEAE & & & & Guapira opposita (Vell.) Reitz & $\mathrm{x}$ & & \\
\hline Cyathea delgadii Sternb. & & $\mathrm{x}$ & & OCHNACEAE & & & \\
\hline EUPHORBIACEAE & & & & Ouratea castaneifolia (DC.) Engl. & $\mathrm{x}$ & & \\
\hline Alchornea glandulosa Poepp. & & & $\mathrm{x}$ & PHYLLANTHACEAE & & & \\
\hline Alchornea triplinervia (Spreng.) Müll. Arg. & & $\mathrm{x}$ & & Hyeronima alchorneoides Allemão & $\mathrm{x}$ & $\mathrm{x}$ & \\
\hline Pera obovata (Klotzch) Baill. & & $\mathrm{x}$ & & PIPERACEAE & & & \\
\hline FABACEAE & & & & Piper arboreum Aubl. & & $\mathrm{x}$ & \\
\hline Andira anthelmia (Vell.) J.F. Macbr. & $\mathrm{x}$ & & & RUBIACEAE & & & \\
\hline Copaifera langsdorffii Desf. & $\mathrm{x}$ & $\mathrm{x}$ & & Amaioua guianensis Aubl. & & & $\mathrm{x}$ \\
\hline Ormosia arborea (Vell.) Harms & & $\mathrm{x}$ & & Coffea arabica $\mathrm{L} . *$ & & $\mathrm{x}$ & \\
\hline Platypodium elegans Vogel & $\mathrm{x}$ & & & Coussarea hydrangeifolia (Benth.) Müll. Arg. & $\mathrm{x}$ & $\mathrm{x}$ & \\
\hline Piptadenia gonoacantha (Mart.) J.F. Macbr. & & & $\mathrm{x}$ & Posoqueria latifolia (Rudge) Roem. \& Schult. & & $\mathrm{x}$ & \\
\hline LACISTEMATACEAE & & & & Psychotria mapourioides DC. & & $\mathrm{x}$ & \\
\hline Lacistema hasslerianum Chodat & $\mathrm{x}$ & & & Psychotria sp. & $\mathrm{x}$ & & \\
\hline LAMIACEAE & & & & Rudgea viburnoides (Cham.) Benth. & $\mathrm{x}$ & & \\
\hline Aegiphila sellowiana Cham. & & & $\mathrm{x}$ & SALICACEAE & & & \\
\hline Vitex polygama Cham. & $\mathrm{x}$ & & & Casearia mariquitensis Kunth & & & $\mathrm{x}$ \\
\hline LAURACEAE & & & & C. sylvestris $\mathrm{Sw}$. & $\mathrm{x}$ & $\mathrm{x}$ & \\
\hline Aniba heringeri Vattimo & $\mathrm{x}$ & & & SAPINDACEAE & & & \\
\hline Nectandra nitidula Nees & & $\mathrm{x}$ & & Cupania vernalis Cambess. & $\mathrm{x}$ & & \\
\hline N. oppositifolia Nees \& Mart. & & & $\mathrm{x}$ & Matayba guianensis Aubl. & & & $\mathrm{x}$ \\
\hline Ocotea corymbosa (Meisn.) Mez & $\mathrm{x}$ & $\mathrm{x}$ & & SIPARUNACEAE & & & \\
\hline O. lancifolia (Schott) $\mathrm{Mez}$ & $\mathrm{x}$ & & & Siparuna guianensis Aubl. & $\mathrm{x}$ & $\mathrm{x}$ & \\
\hline O. pulchella Mart. & $\mathrm{x}$ & & & SOLANACEAE & & & \\
\hline LYTHRACEAE & & & & Cestrum megalophyllum Dunal & & $\mathrm{x}$ & \\
\hline Lafoensia pacari A. St.-Hil. & $\mathrm{x}$ & & & STYRACACEAE & & & \\
\hline MAGNOLIACEAE & & & & Styrax pohlii A. DC. & & $\mathrm{x}$ & \\
\hline Magnolia ovata (A. St.-Hil.) Spreng. & & $\mathrm{x}$ & & THEACEAE & & & \\
\hline MALPIGHIACEAE & & & & Gordonia fruticosa (Schrad.) H. Keng & $\mathrm{x}$ & & \\
\hline Byrsonima cf. ligustrifolia A. St.-Hil. & & $\mathrm{x}$ & & THYMELAEACEAE & & & \\
\hline Byrsonima sp. & & $\mathrm{x}$ & & Daphnopsis fasciculata (Meisn.) Nevling & $\mathrm{x}$ & & \\
\hline MALVACEAE & & & & URTICACEAE & & & \\
\hline Eriotheca candolleana (K. Schum.) A. Robyns & & $\mathrm{x}$ & & Cecropia glaziovi Snethl. & & $\mathrm{x}$ & \\
\hline MELASTOMATACEAE & & & & C. pachystachya Trecul & & $\mathrm{x}$ & \\
\hline Miconia chamissois Naudin & & & $\mathrm{x}$ & VOCHYSIACEAE & & & \\
\hline M. elegans Cogn. & & $\mathrm{x}$ & & Vochysia tucanorum Mart. & & & $\mathrm{x}$ \\
\hline M. pseudonervosa Cogn. & & $\mathrm{x}$ & & WINTERACEAE & & & \\
\hline M. sellowiana Naudin & & & $\mathrm{x}$ & Drimys brasiliensis Miers & & & \\
\hline
\end{tabular}


Tabela 3. Espécies arbustivas e arbóreas $(P A P \geq 10 \mathrm{~cm}$ ) encontradas sobre Cambissolos, em uma floresta paludosa no Município de Cristais Paulista, $\mathrm{SP}$, Brasil. $\mathrm{NI}=$ número de indivíduos amostrados; $\mathrm{DeA}=$ densidade absoluta (indivíduos.ha-1 $)$; DoA = dominância absoluta $\left(\mathrm{m}^{2} \cdot \mathrm{ha}^{-1}\right) ; \mathrm{FA}=$ freqüência absoluta $(\%)$; VI = valor de importância $(\%)$.

\begin{tabular}{|c|c|c|c|c|c|}
\hline Espécies & $\mathrm{NI}$ & DeA & DoA & FA & VI \\
\hline Protium spruceanum & 43 & 538 & 5,84 & 100 & 16,66 \\
\hline Siphoneugena densiflora & 28 & 350 & 3,15 & 88 & 10,76 \\
\hline Tapirira guianensis & 10 & 125 & 4,50 & 63 & 8,66 \\
\hline Ocotea pulchella & 10 & 125 & 4,23 & 63 & 8,35 \\
\hline Virola sebifera & 18 & 225 & 0,74 & 100 & 6,73 \\
\hline Copaifera langsdorffii & 12 & 150 & 2,13 & 75 & 6,62 \\
\hline Xylopia sericea & 18 & 225 & 1,08 & 75 & 6,38 \\
\hline Calophyllum brasiliense & 7 & 88 & 1,23 & 75 & 4,78 \\
\hline Lafoensia pacari & 2 & 25 & 3,13 & 25 & 4,67 \\
\hline Lacistema hasslerianum & 16 & 200 & 0,32 & 50 & 4,44 \\
\hline Andira anthelmia & 3 & 38 & 0,59 & 38 & 2,27 \\
\hline Pseudolmedia laevigata & 6 & 75 & 0,33 & 25 & 2,09 \\
\hline Xylopia emarginata & 3 & 38 & 0,37 & 38 & 2,02 \\
\hline Vitex polygama & 5 & 63 & 0,33 & 25 & 1,93 \\
\hline Myrcia tomentosa & 4 & 50 & 0,14 & 38 & 1,92 \\
\hline Coussarea hydrangeifolia & 2 & 25 & 0,32 & 25 & 1,44 \\
\hline Ocotea corymbosa & 2 & 25 & 0,07 & 25 & 1,14 \\
\hline Myrciaria floribunda & 2 & 25 & 0,08 & 25 & 1,11 \\
\hline Ouratea castaneifolia & 2 & 25 & 0,08 & 25 & 1,09 \\
\hline Siparuna guianensis & 2 & 25 & 0,08 & 25 & 1,09 \\
\hline Geonoma brevispatha & 2 & 25 & 0,08 & 13 & 0,72 \\
\hline Rudgea viburnoides & 1 & 13 & 0,08 & 13 & 0,66 \\
\hline Guapira opposita & 1 & 13 & 0,08 & 13 & 0,58 \\
\hline Eugenia acutata & 1 & 13 & 0,08 & 13 & 0,57 \\
\hline Hyeronima alchorneoides & 1 & 13 & 0,08 & 13 & 0,56 \\
\hline Macropeplus ligustrinus & 1 & 13 & 0,08 & 13 & 0,56 \\
\hline Casearia sylvestris & 1 & 13 & 0,08 & 13 & 0,55 \\
\hline Cupania vernalis & 1 & 13 & 0,08 & 13 & 0,55 \\
\hline Platypodium elegans & 1 & 13 & 0,08 & 13 & 0,55 \\
\hline Psychotria sp. & 1 & 13 & 0,08 & 13 & 0,55 \\
\hline
\end{tabular}

evidenciando os Cambissolos como solos melhor drenados e com maior declive, e os Gleissolos, mais alagados, sobre topografia mais plana e com maior concentração de Fe (Fig. 2A). Entretanto, algumas parcelas estabelecidas sobre Gleissolos também foram caracterizadas por maior profundidade do lençol freático (Fig. 2B) e maior desnível topográfico, de forma que se agruparam, na ordenação, com parcelas sobre os Cambissolos. O eixo 2 separou principalmente o grupo de parcelas inseridas nos Gleissolos em dois subgrupos, de acordo com a porcentagem de abertura do dossel (Fig. 2C). No primeiro subgrupo (no vértice superior direito), a abertura de dossel variou entre $11 \%$ (parcela 23) e 20\% (parcela 31), enquanto no segundo subgrupo (vértice inferior direito) variou entre $26 \%$ (parcela 13) e $43 \%$ (parcela 12). Cada grupo de parcelas teve um conjunto de espécies características (Fig. 2D) e as correlações dessas espécies com as variáveis ambientais mais importantes de cada eixo são apresentadas na Tab. 5.

Das 29 espécies mais abundantes, 19 mostraram-se correlacionadas ou com a profundidade do lençol freático ou com a abertura do dossel (Tab. 5), entretanto um maior número de espécies apresentou correlação com a profundidade do lençol, evidenciando a maior importância das condições hídricas na distribuição das espécies da floresta estudada. Espécies como Calophyllum brasiliense, Geonoma brevispatha, Guarea macrophylla e Xylopia
Tabela 4. Espécies arbustivas e arbóreas (PAP $\geq 10 \mathrm{~cm}$ ) encontradas sobre Gleissolos, em uma floresta paludosa no Município de Cristais Paulista, SP, Brasil. $\mathrm{NI}=$ número de indivíduos amostrados; $\mathrm{De} \mathrm{A}=$ densidade absoluta (indivíduos.ha $\left.\mathrm{a}^{-1}\right)$; DoA $=$ dominância absoluta $\left(\mathrm{m}^{2} \cdot \mathrm{ha}^{-1}\right) ; \mathrm{FA}=$ freqüência absoluta $(\%)$; VI = valor de importância $(\%)$.

\begin{tabular}{|c|c|c|c|c|c|}
\hline Espécies & NI & DeA & DoA & FA & VI \\
\hline Protium spruceanum & 380 & 731 & 11,63 & 96 & 19,35 \\
\hline Calophyllum brasiliense & 344 & 662 & 12,20 & 92 & 18,99 \\
\hline Tapirira guianensis & 146 & 281 & 8,39 & 88 & 12,31 \\
\hline Xylopia emarginata & 183 & 352 & 6,36 & 83 & 11,21 \\
\hline Geonoma brevispatha & 227 & 437 & 0,37 & 83 & 7,41 \\
\hline Guarea macrophylla & 144 & 277 & 0,51 & 67 & 5,44 \\
\hline Hyeronima alchorneoides & 43 & 83 & 1,02 & 42 & 3,10 \\
\hline Myrcia laruotteana & 79 & 152 & 0,36 & 25 & 2,62 \\
\hline Pseudolmedia laevigata & 54 & 104 & 0,30 & 37 & 2,53 \\
\hline Rapanea gardneriana & 31 & 60 & 0,41 & 33 & 2,06 \\
\hline Magnolia ovata & 17 & 33 & 0,29 & 29 & 1,57 \\
\hline Piper arboreum & 29 & 56 & 0,07 & 27 & 1,56 \\
\hline Miconia pseudonervosa & 24 & 46 & 0,06 & 23 & 1,31 \\
\hline Styrax pohlii & 14 & 27 & 0,10 & 25 & 1,24 \\
\hline Aniba heringeri & 11 & 21 & 0,06 & 17 & 0,87 \\
\hline Macropeplus ligustrinus & 14 & 27 & 0,07 & 15 & 0,87 \\
\hline Byrsonima cf. ligustrifolia & 8 & 15 & 0,08 & 13 & 0,69 \\
\hline Psychotria mapourioides & 8 & 15 & 0,01 & 13 & 0,64 \\
\hline Alchornea triplinervia & 5 & 10 & 0,32 & 8 & 0,62 \\
\hline Virola sebifera & 7 & 14 & 0,19 & 8 & 0,55 \\
\hline Miconia elegans & 6 & 12 & 0,02 & 12 & 0,54 \\
\hline Gordonia fruticosa & 6 & 12 & 0,06 & 8 & 0,44 \\
\hline Cyathea delgadii & 4 & 8 & 0,06 & 8 & 0,40 \\
\hline Ocotea corymbosa & 4 & 8 & 0,01 & 8 & 0,36 \\
\hline Nectandra nitidula & 4 & 8 & 0,07 & 6 & 0,33 \\
\hline Pera obovata & 4 & 8 & 0,06 & 4 & 0,26 \\
\hline Cecropia pachystachya & 2 & 4 & 0,04 & 4 & 0,20 \\
\hline Hedyosmum brasiliense & 3 & 6 & 0,01 & 4 & 0,20 \\
\hline Cestrum megalophyllum & 3 & 6 & 0,01 & 4 & 0,20 \\
\hline Duguetia lanceolata & 2 & 4 & 0,02 & 4 & 0,19 \\
\hline Myrcia cf. palustris & 2 & 4 & 0,01 & 4 & 0,18 \\
\hline Siparuna guianensis & 2 & 4 & 0,01 & 4 & 0,18 \\
\hline Schefflera morototoni & 2 & 4 & 0,01 & 4 & 0,18 \\
\hline Siphoneugena densiflora & 2 & 4 & 0,02 & 2 & 0,12 \\
\hline Copaifera langsdorffii & 2 & 4 & 0,02 & 2 & 0,12 \\
\hline Coussarea hydrangeifolia & 2 & 4 & 0,01 & 2 & 0,11 \\
\hline Xylopia sericea & 1 & 2 & 0,03 & 2 & 0,11 \\
\hline Coffea arabica & 2 & 4 & 0,01 & 2 & 0,11 \\
\hline Dendropanax cuneatus & 1 & 2 & 0,02 & 2 & 0,10 \\
\hline Myrcia venulosa & 1 & 2 & 0,01 & 2 & 0,09 \\
\hline Ocotea lancifolia & 1 & 2 & 0,01 & 2 & 0,09 \\
\hline Daphnopsis fasciculata & 1 & 2 & 0,01 & 2 & 0,09 \\
\hline Byrsonima sp. & 1 & 2 & 0,01 & 2 & 0,09 \\
\hline Casearia sylvestris & 1 & 2 & 0,01 & 2 & 0,09 \\
\hline Posoqueria latifolia & 1 & 2 & 0,01 & 2 & 0,09 \\
\hline Calyptranthes grandiflora & 1 & 2 & 0,01 & 2 & 0,09 \\
\hline Cybianthus densicomus & 1 & 2 & 0,01 & 2 & 0,09 \\
\hline
\end{tabular}

emarginata estiveram associadas a solos com lençol freático superficial na estação seca, enquanto Copaifera langsdorffii, Lacistema hasslerianum, Ocotea pulchella, Virola sebifera e Xylopia sericea, entre outras, foram associadas a parcelas com lençol freático mais profundo. C. brasiliense e G. macrophylla também estiveram associadas a parcelas com menor abertura de dossel, enquanto Myrcia laruotteana e X. sericea foram associadas à maior porcentagem de abertura de dossel.

\section{Discussão}

Composição florística e estrutural - O número de espécies encontradas em Cristais Paulista foi superior ao observado 


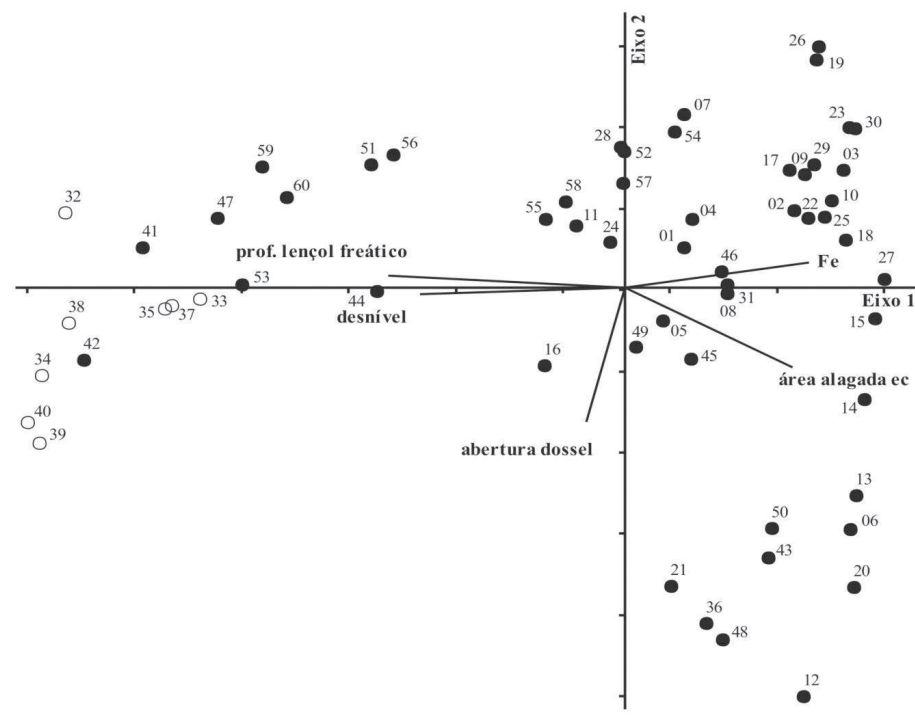

A
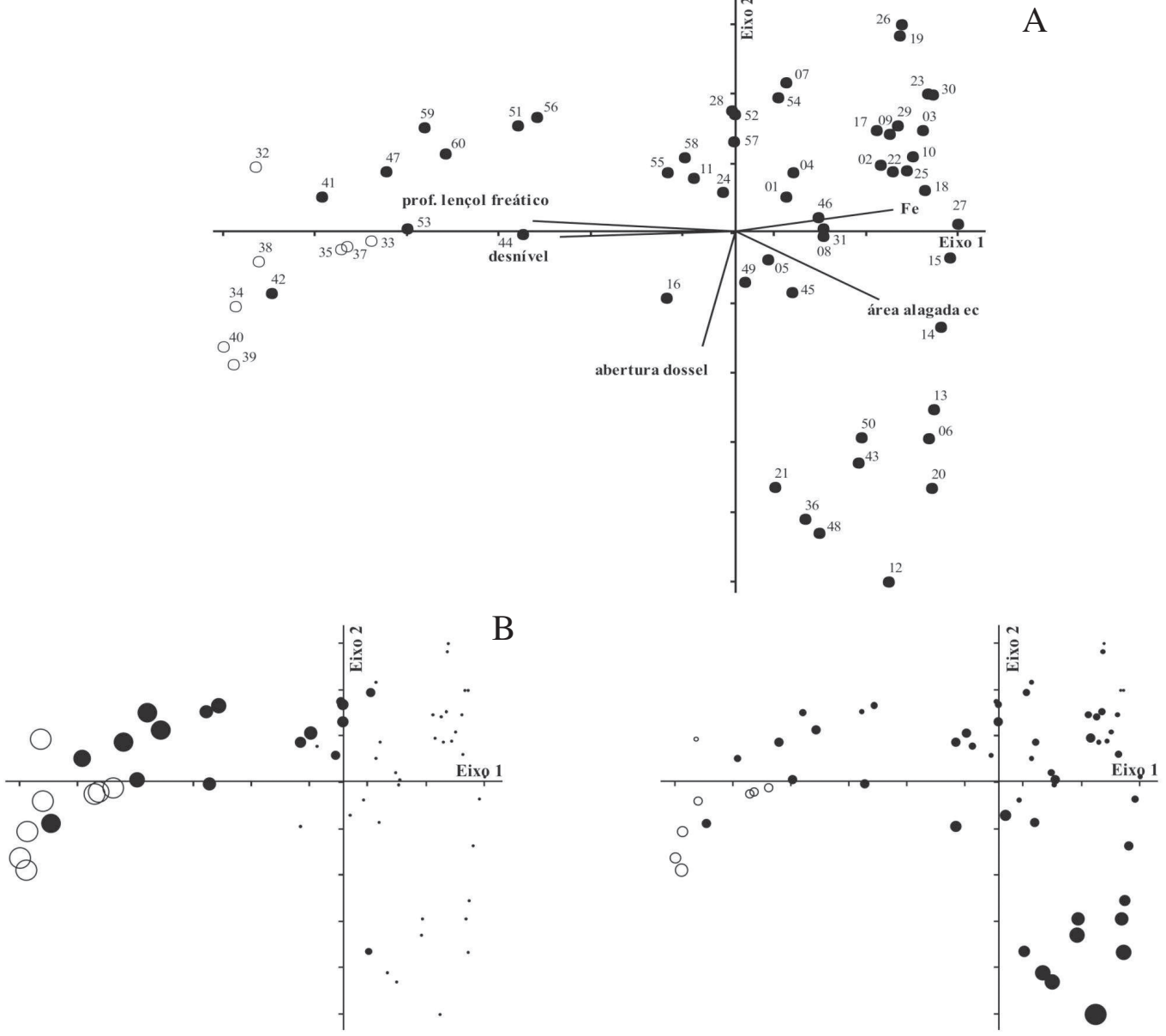

C

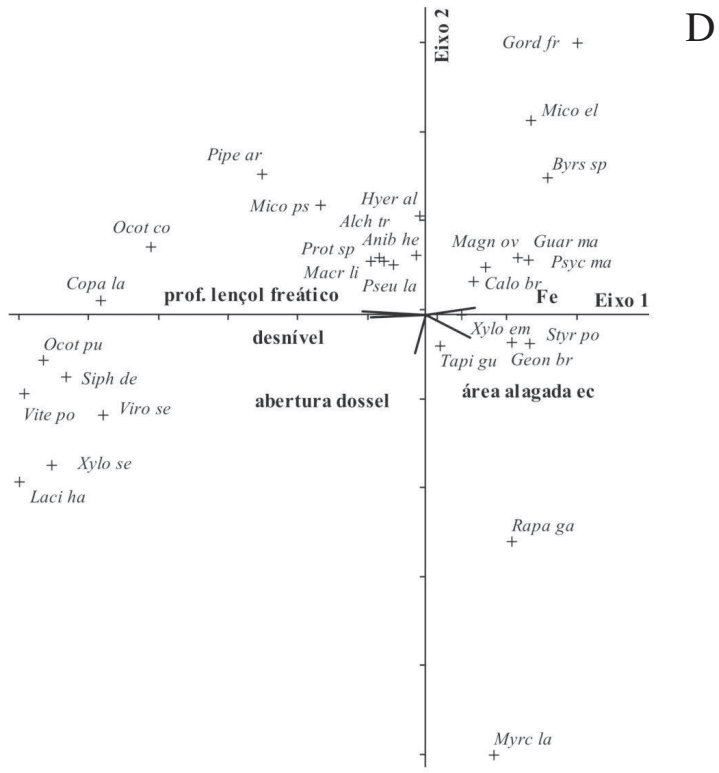

Figura 2. Análise de correspondência canônica: diagramas de ordenação das parcelas de acordo com a densidade de espécies e variáveis ambientais em uma floresta paludosa no Município de Cristais Paulista, SP, Brasil. A. Ordenação das parcelas em função das cinco variáveis ambientais (profundidade do lençol freático, desnível topográfico, Ferro, área alagada na estação seca e abertura do dossel) utilizadas na análise ( $\mathrm{O}=\mathrm{Cambissolos}$; $\bullet=$ Gleissolos $)$. B. Representação das parcelas de acordo com a profundidade do lençol freático (símbolos maiores representam maior profundidade). C. Representação das parcelas de acordo com a abertura do dossel (símbolos maiores representam maior porcentagem de abertura). D. Ordenação das 29 espécies mais abundantes em função das cinco variáveis ambientais utilizadas na análise. A nomenclatura das espécies, cujos nomes foram abreviados, é dada na Tab. 5. 
Tabela 5. Coeficientes de correlação de Spearman $\left(r_{\mathrm{s}}\right)$ entre duas variáveis ambientais e 29 espécies mais abundantes de uma floresta paludosa no Município de Cristais Paulista, SP, Brasil. Os valores de $P$ estão representados entre parêntesis; o negrito indica correlações significativas para $P \leq 0,05(\leq 0,025$ após correção seqüencial de Bonferroni). A abreviação das espécies foi utilizada na análise de correspondência canônica - CCA (Fig. 2B).

\begin{tabular}{|c|c|c|c|}
\hline Espécies & Abreviatura & Lençol freático & Abertura de dossel \\
\hline Alchornea triplinervia & Alch tr & $0,011(0,932)$ & $-0,162(0,216)$ \\
\hline Aniba heringeri & Anib he & $-0,085(0,516)$ & $-0,062(0,637)$ \\
\hline Byrsonima cf. ligustrifolic & ia Byrs sp & $-0,293(0,023)$ & $-0,272(0,035)$ \\
\hline Calophyllum brasiliense & Calo br & $-0,427(0,001)$ & $-0,359(0,005)$ \\
\hline Copaifera langsdorffii & Copa la & $0,474(0,000)$ & $0,163(0,212)$ \\
\hline Geonoma brevispatha & Geon br & $-0,677(0,000)$ & $-0,152(0,248)$ \\
\hline Gordonia fruticosa & Gord $f r$ & $-0,216(0,098)$ & $-0,394(0,002)$ \\
\hline Guarea macrophylla & Guar ma & $-0,576(0,000)$ & $-0,310(0,016)$ \\
\hline Hyeronima alchorneoides & s Hyer al & $-0,186(0,155)$ & $-0,184(0,159)$ \\
\hline Lacistema hasslerianum & Laci ha & $0,449(0,000)$ & $0,250(0,053)$ \\
\hline Macropeplus ligustrinus & Macr li & $-0,050(0,706)$ & $-0,129(0,324)$ \\
\hline Magnolia ovata & Magn ov & $-0,265(0,040)$ & $-0,216(0,098)$ \\
\hline Miconia elegans & Mico el & $-0,269(0,037)$ & $-0,305(0,018)$ \\
\hline Miconia pseudonervosa & Mico ps & $0,191(0,144)$ & $-0,022(0,869)$ \\
\hline Myrcia laruotteana & Myrc la & $-0,177(0,176)$ & $0,296(0,022)$ \\
\hline Ocotea corymbosa & Ocot co & $0,357(0,005)$ & $0,077(0,559)$ \\
\hline Ocotea pulchella & Ocot pu & $0,506(0,000)$ & $0,160(0,221)$ \\
\hline Piper arboreum & Pipe ar & $0,411(0,001)$ & $0,087(0,507)$ \\
\hline Protium spruceanum & Prot sp & $-0,017(0,900)$ & $-0,276(0,032)$ \\
\hline Rapanea gardneriana & Rapa ga & $-0,408(0,001)$ & $0,152(0,245)$ \\
\hline Pseudolmedia laevigata & Pseu la & $-0,148(0,259)$ & $-0,146(0,267)$ \\
\hline Psychotria mapourioides & Psyc ma & $-0,229(0,078)$ & $-0,152(0,247)$ \\
\hline Siphoneugena densiflora & Siph de & $0,541(0,000)$ & $0,260(0,045)$ \\
\hline Styrax pohlli & Styr po & $-0,303(0,018)$ & $-0,249(0,055)$ \\
\hline Tapirira guianensis & Tapi gu & $-0,232(0,075)$ & $0,010(0,937)$ \\
\hline Virola sebifera & Viro se & $0,672(0,000)$ & $0,279(0,030)$ \\
\hline Vitex polygama & Vite po & $0,312(0,015)$ & $0,139(0,291)$ \\
\hline Xylopia emarginata & Xylo em & $-0,299(0,020)$ & $-0,084(0,525)$ \\
\hline Xylopia sericea & Xylo se & $0,491(0,000)$ & $0,337(0,008)$ \\
\hline
\end{tabular}

em outras florestas paludosas no Brasil, que de modo geral detiveram de 30 a 60 espécies (ver Silva et al. 2007). Embora os diferentes critérios de inclusão dos indivíduos e os esforços amostrais muito distintos dificultem uma comparação mais precisa entre as florestas, a riqueza encontrada corrobora um padrão que emergiu com os estudos recentes: o incremento da riqueza florística dessas florestas tem sido relatado em função das diferentes condições edáficas locais e da interface com outros tipos florestais (Marques et al. 2003; Rocha et al. 2005; Teixeira et al. 2008), de forma que, sob essas condições, o número de espécies pode chegar a 100 ou mais (Rocha et al. 2005; Loures et al. 2007).

De forma similar às demais florestas paludosas Neotropicais, a estrutura da vegetação estudada foi determinada pela concentração de muitos indivíduos em poucas espécies, principalmente nos trechos mal drenados (Gleissolos). De modo geral, destacaram-se Protium spruceanum, Calophyllum brasiliense, Tapirira guianensis, Xylopia emarginata e Geonoma brevispatha, que perfizeram $66 \%$ dos indivíduos quantificados. Essa prevalência de poucas espécies é responsável pelo baixo valor de diversidade $\left(\mathrm{H}^{\prime}\right)$ dessas formações, que quase sempre é inferior a 3, podendo ser inclusive inferior ou próximo a 2 (Waechter \& Jarenkow 1998; Teixeira \& Assis 2005; Scarano 2006). A comparação com outras florestas paludosas estudadas no sudeste do Brasil (excluindo a região costeira) e no Brasil central, denominadas de floresta de galeria inundável, evidencia que muitas espécies importantes em cada comunidade são comuns às duas regiões, como Calophyllum brasiliense, Dendropanax cuneatus, Euterpe edulis, Guarea macrophylla, Magnolia ovata, Protium spruceanum e Tapirira guianensis (Torres et al. 1994; Ivanauskas et al. 1997; Toniato et al. 1998; Guarino \& Walter 2005; Teixeira \& Assis 2005; Dietzsch et al. 2006). Entretanto, Xylopia emarginata, quarta espécie com maior valor de importância no presente estudo, e muito comum nas florestas paludosas do Brasil central (Oliveira Filho et al. 1990; Guarino \& Walter 2005; Dietzsch et al. 2006), tem sua distribuição restrita às florestas paludosas do sudeste inseridas em uma matriz de Cerrado. Nessa situação, a espécie teve grande importância em florestas paludosas estudadas em Uberlândia, MG (Nogueira \& Schiavini 2003), Bauru, SP (M. Carboni, dados não publicados) e Itirapina, SP (A.P. Teixeira, M.A. Assis e B.G. Luize, dados não publicados). Outra espécie marcante das florestas de galeria de Minas Gerais e do Brasil central, principalmente no subtipo inundável, é Pseudolmedia laevigata, que deteve o oitavo VI em Cristais Paulista. Essa espécie ainda não havia sido registrada em outras florestas paludosas no Estado de São Paulo. A afinidade florística entre as florestas paludosas do sudeste e do Brasil central foi destacada por Guarino \& Walter (2005). Os autores observaram que, além das espécies, muitos gêneros são comuns às florestas paludosas das duas regiões, como Cyathea, Ficus, Geonoma, Ilex, Ocotea, Protium e Styrax. Desses gêneros, apenas Ilex não foi encontrado no presente estudo, confirmando a observação dos autores.

Das famílias representadas por um maior número de espécies em Cristais Paulista, Euphorbiaceae, Fabaceae, Lauraceae e Myrtaceae estiveram, juntamente com Meliaceae, entre as mais ricas em florestas paludosas do interior do Brasil (Torres et al. 1994; Costa et al. 1997; Ivanauskas et al. 1997; Toniato et al. 1998; Paschoal \& Cavassan 1999; Marques et al. 2003, Rocha et al. 2005; Guarino \& Walter 2005; Teixeira \& Assis 2005; Loures et al. 2007). Já a riqueza de Melastomataceae e Rubiaceae pode estar associada ao critério adotado para inclusão dos indivíduos, que possibilitou a amostragem de representantes de sub-bosque. Em outras florestas interioranas, como as semideciduais e ribeirinhas sobre melhores condições de drenagem, Euphorbiaceae, Fabaceae, Lauraceae, Meliaceae e Myrtaceae foram, juntamente com Rutaceae, as mais bem representadas (Leitão Filho 1982; Pagano \& Leitão Filho 1987; Rodrigues et al. 1989; Salis et al. 1994; Silva et al. 1995), de forma que a riqueza de espécies não se mostra um bom parâmetro para distinguir famílias típicas de florestas paludosas. Entretanto, enquanto as famílias mais ricas são também as mais importantes naquelas florestas, as poucas espécies prevalentes nas florestas paludosas influenciam no maior valor de importância das famílias às quais pertencem, sendo Anacardiaceae, Burseraceae, Clusiaceae, 
Magnoliaceae e Meliaceae destacadas como mais importantes na maioria dos estudos (e.g. Ivanauskas et al. 1997; Toniato et al. 1998; Marques et al. 2003; Teixeira \& Assis 2005). Um fato marcante é que Fabaceae, muito expressiva tanto em número de espécies quanto em densidade de indivíduos nas formações Neotropicais, é uma família pouco importante (em VI) em florestas paludosas interioranas. A família é expressiva apenas em algumas florestas paludosas no domínio Amazônico, onde são favorecidas pela simbiose com bactérias noduladoras (Koponen et al. 2003; 2004).

Distribuição de espécies e variações ambientais - Nossos resultados demonstraram que as condições edáficas e a composição das espécies da floresta estudada variaram em uma escala espacial reduzida, de poucas centenas metros. Em função da maior permanência da água na superfície do solo, o fundo do vale foi caracterizado pela maior concentração de matéria orgânica, por ter sua decomposição reduzida, soma de bases e Fe. No fundo de vale, a drenagem mais deficiente pode ter determinado vantagens competitivas para algumas espécies, resultando em uma maior dominância ecológica e menor diversidade em comparação com os trechos melhor drenados. A saturação hídrica do solo tem sido apontada como agente primário na determinação das características físicas, químicas e biológicas dos solos (Hughes 1990) e exerce importante função na estruturação das comunidades vegetais em florestas ribeirinhas. $\mathrm{O}$ incremento de matéria orgânica, bases e Fe com o aumento da saturação hídrica do solo também foi relatado por Budke et al. (2008), em uma floresta ribeirinha no sul do Brasil.

As condições topográficas associadas à geologia, aos solos e ao regime de chuvas local determinam o hidroperíodo, que é caracterizado principalmente pela freqüência e duração da permanência da água no solo, assim como pela altura da lâmina d'água (Lugo et al. 1990). Nas margens do curso d'água da floresta estudada, a topografia mais plana e o lençol freático próximo à superfície favorecem a maior freqüência de inundações em relação aos trechos mais declivosos. Dessa forma, as inundações no fundo de vale podem ocorrer de acordo com o regime pluviométrico local e permanecer por dias ou meses. Essas condições determinam maior instabilidade desses solos e, conseqüentemente, uma maior variação na abertura do dossel (entre 11 e 43\%), resultando em uma vegetação distinta e mais dinâmica do que aquela associada aos solos mais bem drenados. A diversidade de espécies nos Gleissolos (fundo de vale) foi inferior aos trechos de maior declive sobre Cambissolos, onde a água permanece por menos tempo na superfície, provavelmente em função da saturação hídrica, visto que poucas espécies desenvolveram mecanismos que possibilitam a colonização de ambientes mais estressantes (Joly 1991). A relação entre o incremento da saturação hídrica dos solos e o decréscimo dos valores de diversidade corrobora outros estudos em florestas paludosas Neotropicais (Koponem et al. 2004; Scarano 2006; Teixeira et al. 2008).
A heterogeneidade ambiental da área estudada mostrou-se como um importante fator que determina a distribuição e a coexistência de espécies com diferentes exigências às condições microambientais, visto que $66 \%$ das espécies mais abundantes estiveram associadas ou a profundidade do lençol freático na estação seca ou a abertura do dossel. Além disso, apenas Protium spruceanum e Tapirira guianensis estiveram entre as espécies de maior VI nos dois tipos de solo, independentemente das condições ambientais. Enquanto T. guianensis é uma espécie generalista, de ampla ocorrência geográfica, que ocorre nos cerrados e em diversos tipos florestais (Oliveira Filho \& Ratter 1995), P. sprucenaum ocorre amplamente pelas florestas paludosas, em microsítios bem ou mal drenados (Silva et al. 2007; Teixeira et al. 2008). Por outro lado, espécies como Calophyllum brasiliense, Geonoma brevispatha, Guarea macrophylla, Hyeronima alchorneoides, Rapanea gardneriana e Xylopia emarginata prevaleceram nos Gleissolos, no fundo de vale, e juntamente com Styrax pohlii estiveram associadas aos solos mal drenados. Essas espécies são destacadas como espécies típicas de ambientes inundáveis em florestas de galeria (Sampaio et al. 2000; Correia et al. 2001). Outras espécies típicas de solos mal drenados, que foram encontradas no presente estudo, incluem Euterpe edulis, Macropeplus ligustrinus, Magnolia ovata, Miconia chamissois, Psychotria mapourioides e Tabebuia umbellata (Walter \& Ribeiro 1997).

Espécies como Copaifera langsdorffii, Lacistema hasslerianum, Ocotea corymbosa, O. pulchella, Siphoneugena densiflora, Virola sebifera e Xylopia sericea, associadas aos solos de melhor drenagem da área de estudo (Cambissolos), são pouco comuns em florestas paludosas, mas apresentam incremento na densidade em florestas de galeria sobre solos bem drenados, florestas estacionais semideciduais e também nos cerrados (Araújo \& Haridassan 1997; Walter \& Ribeiro 1997; Teixeira et al. 2004; Teixeira \& Rodrigues 2006). Outras espécies encontradas em Cristais Paulista e que também prevalecem sobre solos bem drenados incluem Cupania vernalis, Matayba guianensis, Myrcia splendens, M. tomentosa, Rapanea ferruginea, Rudgea viburnoides, Siparuna guianensis, Vitex polygama e Vochysia tucanorum, entre outras. A maioria dessas espécies foi observada em uma floresta de galeria não sujeita a alagamentos, na mesma microbacia hidrográfica da floresta estudada, sendo que V. sebifera, T. guianensis, C. langsdorffii, M. splendens, $S$. guinanensis, $X$. sericea e $O$. pulchella figuraram entre as espécies com maiores VI da floresta (Teixeira \& Rodrigues 2006). Dessa forma, a comunidade estabelecida sobre os Cambissolos apresenta composição florística semelhante às florestas de galeria não inundável.

As espécies em comum com os outros tipos vegetacionais como os cerrados, florestas de galeria e semideciduais, encontradas principalmente sobre Cambissolos, evidenciam que muitas espécies generalistas 
são compartilhadas com a floresta estudada. Essa flora compartilhada é atribuída ao fato de que a umidade do solo nas bordas das florestas ribeirinhas é relativamente mais baixa do que no seu interior (Oliveira Filho \& Ratter 1995). Esse fato permite o estabelecimento de espécies típicas de solos bem drenados tanto na borda quanto em sítios bem drenados de florestas ribeirinhas. Já Myrcia laruottena, espécie comum de florestas paludosas e aluviais (Silva et al. 2007), esteve associada, juntamente com $X$. sericea, a trechos com maior abertura de dossel. Outras espécies encontradas na floresta estudada que ocorrem principalmente em trechos de maior incidência luminosa, como bordas e clareiras de florestas ribeirinhas, incluem Cecropia pachystachya e Hedyosmum brasiliense (Sampaio et al. 2000).

As diferentes condições ambientais da área estudada, relacionadas aos tipos de solo, topografia, condições de drenagem e abertura de dossel determinam mosaicos de associações de espécies, que variam conforme o microambiente. Nessas condições, espécies com diferentes exigências às condições edáficas e de luminosidade coexistem, resultando em um incremento na diversidade local. A heterogeneidade ambiental interna da floresta, associada à sua localização geográfica são responsáveis por uma flora diversificada, que inclui elementos de diferentes tipos florestais e cerrados. Essas características devem ser consideradas nos planos de conservação dos remanescentes da região.

\section{Agradecimentos}

Agradecemos a CAPES, pela bolsa de doutorado concedida ao primeiro autor; FAPESP, pelo auxílio pesquisa (proc. 07/52613-5); Idea Wild, pela doação de equipamentos para trabalho de campo; Sr. Galvão, pela autorização para desenvolver o trabalho na fazenda Tamboril; Jairo J. Rueda, pela ajuda na classificação dos solos; José C. Casagrande e José G. Peres, pela análise das propriedades químicas e granulométricas das amostras de solo; João B. Baitello (Lauraceae), Marcos Sobral (Myrtaceae), Rodrigo A.S. Pereira (Ficus), Sérgio Romaniuc Neto (Pseudolmedia), Renato Goldenberg (Miconia), Vinícius A.O. Dittrich (Cyathea), pela ajuda na identificação das espécies; Dalila V. Freitas, pela tradução do abstract e confecção do mapa; Alexandre C. Oliveira, Dalila V. Freitas e Eliseu A.T. Neto, pela ajuda nos trabalhos de campo; Dr. Steven M. Holland, pela disponibilidade gratuita do programa Analytic Rarefaction 1.3, no site http://www.uga.edu/strata/software/AnRareReadme.html; assessores anônimos, pelas sugestões.

\section{Referências bibliográficas}

APG II - Angiosperm Phylogeny Group. 2003. An update of the Angiosperm Phylogeny Group classification for the orders and families of flowering plants. Botanical Journal of the Linnean Society 141: 399-436.

Almeida, F.F.M. 1974. Fundamentos geológicos do relevo paulista. São Paulo, Universidade de São Paulo, Instituto de Geografia.

Araújo, G.M. \& Haridassan, M. 1997. Estrutura fitossociológica de duas matas mesófilas semidecíduas, em Uberlândia, Triângulo Mineiro. Naturalia 22: 115-129.

Budke, J.C.; Jarenkow, J.A. \& Oliveira Filho, A.T. 2008. Tree community features of two stands of riverine forest under different flooding regimes in Southern Brazil. Flora 203: 162-174.
Correia, J.R.; Haridassan, M.; Reatto, A.; Martins, E.S. \& Walter, B.M. 2001. Influência dos fatores edáficos na distribuição de espécies arbóreas em matas de galeria na região do cerrado: uma revisão. Pp. 51-76. In: J.F. Ribeiro, C.E.L. Fonseca \& J.C. SouzaSilva (eds.). Cerrado: caracterização e recuperação de matas de galeria. Planaltina, Embrapa.

Costa, F.R.C.; Schlittler, F.H.M.; César, O. \& Monteiro, R. 1997. Aspectos florísticos e fitossociológicos de um remanescente de brejo no Município de Brotas, SP. Arquivos de Biologia e Tecnologia 40: 263-270.

Damasceno Junior, G.A.; Semir, J.; Santos, F.A.M. \& Leitão Filho, H.F. 2005. Structure, distribution of species and inundation in a riparian forest of Rio Paraguai, Pantanal, Brazil. Flora 200: 119-135.

Dietzsch, L.; Rezende, A.V.; Pinto, J.R.R. \& Pereira, B.A.S. 2006. Caracterização da flora arbórea de dois fragmentos de mata de galeria do Parque Canjerana, DF. Cerne 12: 201-210.

Embrapa 1999. Sistema Brasileiro de Classificação de Solos. Rio de Janeiro, Empresa Brasileira de Pesquisa Agropecuária \& Centro Nacional de Pesquisa de Solos.

Felfili, J.M. 1995. Diversity, structure and dynamics of a gallery forest in central Brazil. Vegetatio 117: 1-15.

Frazer, G.W.; Canham, C.D. \& Lertzman, K.P. 1999. Gap Light Analyzer (GLA), Version 2.0: Imaging software to extract canopy structure and gap light transmission indices from truecolour fisheye photographs, users manual and program documentation. New York, Simon Fraser University, Burnaby, British Columbia, and the Institute of Ecosystem Studies.

Guarino, E.S.G. \& Walter, B.M.T. 2005. Fitossociologia de dois trechos inundáveis de matas de galeria no Distrito Federal, Brasil. Acta Botanica Brasilica 19: 431-442.

Hughes, F.M.R. 1990. The influence of flooding regimes on forest distribution and composition in the Tana River floodplain, Kenya. Journal of Applied Ecology 27: 475-491.

Ivanauskas, N.M.; Rodrigues, R.R. \& Nave, A.G. 1997. Aspectos ecológicos de uma mata de brejo em Itatinga, SP: florística, fitossociologia e seletividade de espécies. Revista Brasileira de Botânica 20: 139-153.

Joly, C.A. 1991. Flooding tolerance in tropical trees. Pp. 23-43. In: M.B. Jackson; D.D. Davies \& H. Lambers (eds.). Plant life under oxygen deprivation: ecology, physiology and biochemistry. The Hague, SBP Academic Publishing.

Koponen, P.; Nygren, P.; Domenach, A.M.; Roux, C.L.; Saur, E. \& Roggy, J.C. 2003. Nodulation and dinitrogen fixation of legume trees in a tropical freshwater swamp forest in French Guiana. Journal of Tropical Ecology 19: 665-666.

Koponen, P.; Nygren, P.; Sabatier, D.; Rousteau, A. \& Saur, E. 2004. Tree species diversity and forest structure in relation to microtopography in a tropical freshwater swamp forest in French Guiana. Plant Ecology 173: 17-32.

Leitão Filho, H.F. 1982. Aspectos taxonômicos das florestas do Estado de São Paulo. Silvicultura em São Paulo 16A: 197-206.

Lieberman, M.; Lieberman, D.; Hartshorn, G.S. \& Peralta, R. 1985. Small-scale altitudinal variation in lowland wet tropical forest vegetation. Journal of Ecology 73: 505-516.

Loures, L.; Carvalho, D.A.; Machado, EL.M. \& Marques, J.J.G.S.M. 2007. Florística, estrutura e características do solo de um fragmento de floresta paludosa no sudeste do Brasil. Acta Botanica Brasilica 21: 885-896.

Lugo, A.E.; Brown, S. \& Brinson, M.M. 1990. Concepts in wetland ecology. Pp. 53-85. In: A.E. Lugo; M.M. Brinson \& S. Brown (eds.). Ecosystems of the world 15: Forested wetlands. Amsterdam, Elsevier.

Marques, M.C.M.; Silva, S.M. \& Salino, A. 2003. Florística e estrutura do componente arbustivo-arbóreo de uma floresta higrófila da bacia do rio Jacaré-Pepira, SP, Brasil. Acta Botanica Brasilica 17: 495-506.

McCune, B. \& Mefford, M.J. 1999. PC-ORD. Multivariate analysis of ecological data, version 4.0. Oregon Glaneden Beach, MjM Software Desing. 
Nogueira, M.F. \& Schiavini, I. 2003. Composição florística e estrutura da comunidade arbórea de uma mata de galeria inundável em Uberlândia, MG, Brasil. Bioscience Journal 19: 89-98.

Oliveira Filho, A.T.; Ratter, J.A. \& Shepherd, G.J. 1990. Floristic composition and community structure of a Brazilian gallery forest. Flora 184: 103-117.

Oliveira Filho, A.T. \& Ratter, J.A. 1995. A study of the origin of Central Brazilian forests by the analysis of plants species distribution patterns. Edinburgh Journal of Botany 52: $141-194$.

Pagano, S.N. \& Leitão Filho, H.F. 1987. Composição florística do estrato arbóreo de mata mesófila semidecídua no Município de Rio Claro (Estado de São Paulo). Revista Brasileira de Botânica 10: $34-47$.

Paschoal, M.E.S. \& Cavassan, O. 1999. A flora arbórea da mata de brejo do ribeirão do Pelintra, Agudos, SP. Naturalia 24: $171-191$

Raij, B. van. 1983. Avaliação da fertilidade do solo. Piracicaba, Editora Franciscana (LAFRAME).

Ribeiro, J.F. \& Walter, B.M.T. 1998. Fitofisionomias do bioma cerrado. Pp. 89-166. In: S.M. Sano \& S.P. Almeida (eds.). Cerrado: ambiente e flora. Planaltina, EMBRAPA-CPAC.

Rocha, C.T.V.; Carvalho, D.A.; Fontes, M.A.L.; Oliveira Filho, A.T.; van den Berg, E. \& Marques, J.J.G.S.M. 2005. Comunidade arbórea de um continuum entre floresta paludosa e de encosta em Coqueiral, Minas Gerais, Brasil. Revista Brasileira de Botânica 28: 203-218.

Rodrigues, R.R.; Morellato, L.P.C.; Joly, C.A. \& Leitão Filho, H.F. 1989. Estudo florístico e fitossociológico em um gradiente altitudinal de mata estacional mesófila semidecídua, na Serra do Japi, Jundiaí, SP. Revista Brasileira de Botânica 12: 71-84.

Salis, S.M.; Tamashio, J.Y. \& Joly, C.A. 1994. Florística e fitossociologia do estrato arbóreo de um remanescente de mata ciliar do Rio Jacaré Pepira, Brotas, SP. Revista Brasileira de Botânica 17: 93-103

Sampaio, A.B.; Walter, B.M.T. \& Felfili, J.M. 2000. Diversidade e distribuição de espécies arbóreas em duas matas de galeria na microbacia do Riacho Fundo, Distrito Federal. Acta Botanica Brasilica 14: 197-214.

Scarano, F.R.; Ribeiro, K.T.; Moraes, L.F.D. \& Lima, H.C. 1997. Plant establishment on flooded and unflooded patches of a freshwater swamp forest in southeastern Brazil. Journal of Tropical Ecology 14: 793-803.

Scarano, F.R. 2002. Structure, function and floristic relationships of plant communities in stressful habitats marginal to the Brazilian Atlantic rainforest. Annals of Botany 90: 517-524.

Scarano, F.R. 2006. Plant community structure and function in a swamp forest within the Atlantic rain forest complex: a synthesis. Rodriguésia 57: 491-502.

Setzer, J. 1966. Atlas climático e ecológico do Estado de São Paulo. São Paulo, Comissão interestadual da Bacia Paraná-Uruguai.
Shepherd, G.J. 1994. Fitopac 1. Manual do usuário. Departamento de Botânica. Universidade Estadual de Campinas.

Silva, A.C.; van den Berg, E.; Higuchi, P. \& Oliveira Filho, A.T. 2007. Comparação florística de florestas inundáveis das regiões Sudeste e Sul do Brasil. Revista Brasileira de Botânica 30: 257-269.

Silva, F.C.; Fonseca, E.P.; Soares Silva, L.H.; Muller, C. \& Bianchini, E. 1995. Composição florística e fitossociologia do componente arbóreo das florestas ciliares da bacia do Rio Tibagi. 3. Fazenda Bom Sucesso, Município de Sapopema, PR. Acta Botanica Brasilica 9: 289-302.

Souza, A.F. \& Martins, F.R. 2005. Spatial variation and dynamics of flooding, canopy openness, and structure in a Neotropical swamp forest. Plant Ecology 180: 161-173.

Teixeira, A.P. \& Assis, M.A. 2005. Caracterização florística e fitossociológica do componente arbustivo-arbóreo de uma floresta paludosa no Município de Rio Claro (SP), Brasil. Revista Brasileira de Botânica 28: 467-476.

Teixeira, A.P. \& Rodrigues, R.R. 2006. Análise florística e estrutural do componente arbustivo-arbóreo de uma floresta de galeria no Município de Cristais Paulista, SP, Brasil. Acta Botanica Brasilica 20: 803-813.

Teixeira, A.P.; Assis, M.A.; Siqueira, F.R. \& Casagrande, J.C., 2008. Tree species composition and environmental relationships in a Neotropical swamp forest in Southeastern Brazil. Wetlands Ecology and Management 16: 451-461.

Teixeira, M.I.J.G.; Araújo, A.R.; Valeri, S.V. \& Rodrigues, R.R. 2004. Florística e fitossociologia de área de cerrado s.s. no Município de Patrocínio Paulista, nordeste do Estado de São Paulo. Bragantia 63: $1-11$.

ter Braak, C.J.F. 1987. The analysis of vegetation-environment relationships by canonical correspondence analysis. Vegetatio 69: 69-77.

Toniato, M.T.Z.; Leitão Filho, H.F. \& Rodrigues, R.R. 1998 Fitossociologia de um remanescente de floresta higrófila (mata de brejo) em Campinas, SP. Revista Brasileira de Botânica 21: 197-210.

Torres, R.B.; Matthes, L.A.F. \& Rodrigues, R.R. 1994. Florística e estrutura do componente arbóreo de mata de brejo em Campinas, SP. Revista Brasileira de Botânica 17: 189-194.

van Andel, T.R. 2003. Floristic composition and diversity of three swamp forests in northwest Guyana. Plant Ecology 167: 293-317.

Waechter, J.L. \& Jarenkow, J.A. 1998. Composição e estrutura do componente arbóreo nas matas turfosas do Taim, Rio Grande do Sul. Biotemas 11: 45-69.

Walter, B.M.T. \& Ribeiro, J.F. 1997. Spatial floristic patterns in gallery forests in the cerrado region, Brazil. Pp. 339-349. In: J. Imanã-Encinas \& C. Kleinn (eds.). Proceedings of the International Symposium on assessment and monitoring of forests in tropical dry regions with special reference to gallery forests. Brasília, University of Brasília. 